\title{
Observation of Wind Direction Change on the Sea Surface Temperature Front Using High-Resolution Full Polarimetric SAR Data
}

\author{
Kim Tae-Sung ${ }^{1 \stackrel{\star}{-}}$, Park Kyung-Ae ${ }^{1}$, Li Xiaofeng ${ }^{2}$, Mouche Alexis ${ }^{3}$, Chapron Bertrand ${ }^{3}$, Lee Moonjin ${ }^{4}$ \\ ${ }^{1}$ Department of Earth Science Education, Seoul National University, Seoul08826, South Korea \\ ${ }^{2}$ GST at National Oceanic and Atmospheric Administration/National Environmental Satellite, Data, and \\ Information Service, College Park, MD 20740, USA \\ ${ }^{3}$ CERSAT, IFREMER, Plouzané29280, France \\ ${ }^{4}$ Maritime Safety Research Division, Korea Research Institute of Ships and Ocean Engineering, \\ Daejon34103, South Korea \\ Email addresses : taesungkim@snu.ac.kr ; kapark@snu.ac.kr ; xiaofeng.li@noaa.gov ; \\ amouche@ifremer.fr ; bchapron@ifremer.fr ; moonjin.lee@kriso.re.kr
}

\begin{abstract}
:
In this study, we derive high-resolution wind speeds and directions from full-polarization synthetic aperture radar (SAR) data. Previous wind retrieval result from conventional single-polarization SAR data has a limitation to resolve small-scale structures in the surface wind because external wind direction data with coarser spatial resolution than those of SARs have been commonly used as an input. Using fully polarimetric SAR data, however, both wind speed and direction can be derived with high resolution from the image itself without any ancillary data. We derive wind field off the southern coast of Korea from the Radarsat-2 quad-polarization data and investigate the spatial variation. The retrieved wind field from the Radarsat-2 image presents a detailed structure including small-scale variations which is unobtainable from conventional wind observations. Comparison of the derived wind directions with insitu buoy wind measurements shows a small difference of $8^{\circ}$ which is regarded as sufficient to analyze small-scale wind vector changes. The retrieved wind field off the southern coast of Korea demonstrates the distinct patterns of direction changes. While blowing over the sea surface temperature (SST) frontal zone, the veering angles of wind vectors decrease and then are restored. The analysis of SAR-derived wind vectors with coinciding temperature distributions confirms that the variation in SAR-derived wind vectors on the SST fronts is mainly induced by the stability effect. This study also addresses the important role of precise wind direction retrieval on the accuracy of retrieved wind speed.
\end{abstract}

Keywords : wind direction, Full-polarization synthetic aperture radar (SAR), sea surface temperature (SST) front, sea surface wind field, stability effect 


\section{Introduction}

Satellite-based wind measurements have provided us synoptic views of wind fields with an opportunity to understand oceanographic phenomena and their scientific processes. With increasing interest in global climate change, the importance of wind field observation has been more strongly emphasized. Since the early 1990's, satellite scatterometers such as the NASA Scatterometer (NSCAT), Quick Scatterometer (QuikSCAT), and Advanced Scatterometer

(ASCAT) have produced a vast of wind field observations which provide approximately $90 \%$ of the global ocean surface winds at least two times a day, with a spatial resolution of $25 \mathrm{~km}$ over 10 years [1]. The wind vector measurements from space have contributed to understanding the diverse aspects of new scientific discoveries including ocean general circulation, tropical cyclone and hurricane mechanisms, and atmosphere-ocean interaction [2]-[9]. However, their low spatial resolution limits their applicability to observe coastal phenomena and small-scale features related to air-sea interaction.

Synthetic aperture radar (SAR) is capable of high-resolution imaging that allows for the derivation of a detailed wind field with a spatial resolution of less than $1 \mathrm{~km}$, even along coastal regions that were unobtainable with scatterometer observations. This makes it possible to investigate the spatial variability of near-coastal and finer-scale wind fields [10]-[20]. In this respect, SAR-derived wind fields have been used in various applications, including coastal environmental monitoring [21]-[24], the marine atmospheric boundary layer phenomena studies [25]-[31], and the mapping global wind power [32]-[36]. In general, the SAR-based wind information has been derived from single-polarization SAR data using the geophysical model functions (GMFs) that describe the dependence of the normalized radar cross section (NRCS) on the wind speed, relative wind direction to the radar-viewing angle, incidence angle, and polarization state. From the empirical relationship functions of each GMF, the solutions for wind speed and direction can be derived. In the case of the C-band, empirical GMFs, such as CMOD4 [37], CMOD_IFR2 [38], CMOD5 [39] and CMOD5.N [40], have been widely used for the C-band SAR wind retrieval.

However, unlike scatterometry that measures multiple NRCSs at different azimuth viewing angles, the SAR observations are commonly measured from only one viewing direction so that it is necessary to know the wind direction prior to applying the wind retrieval models. It should be noted that 

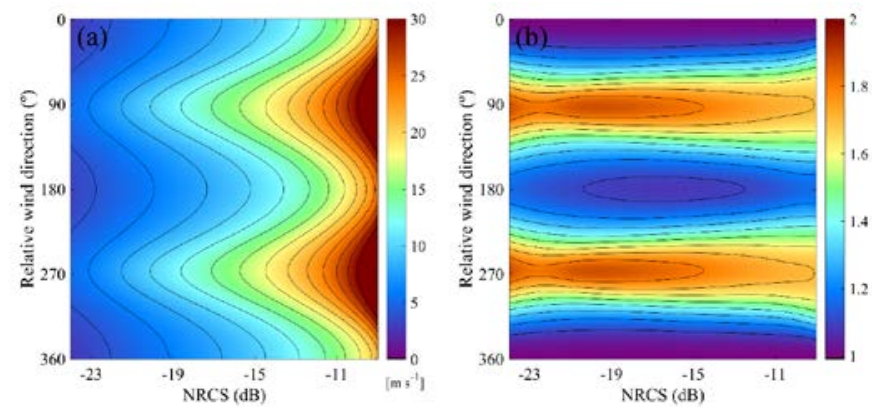

Fig. 1. Distributions of (a) estimated wind speeds $\left(\mathrm{m} \mathrm{s}^{-1}\right)$ as a function of the NRCS $(\mathrm{dB})$ and wind direction $\left({ }^{\circ}\right)$ at a given incidence angle $\left(45^{\circ}\right)$ using the CMOD5.N algorithm and (b) ratios of wind speeds divided by the minimum value of wind speed for a given value.

the estimation of wind speed relies on wind direction retrieval. Fig. 1 presents wind speeds as a function of the NRCS, the relative wind direction calculated by the CMOD5.N algorithm corresponding to an assumed incidence angle of $45^{\circ}$, and ratios of wind speeds divided by the minimum value of wind speeds for a given NRCS value. For the same value of NRCS, the calculated wind speeds vary significantly with the relative wind direction input values. For example, for an NRCS value of -15 $\mathrm{dB}$, the estimated wind speeds range from $9.4 \mathrm{~m} \mathrm{~s}^{-1}$ to $17.1 \mathrm{~m}$ $\mathrm{s}^{-1}$. The maximum difference amounts to $7.7 \mathrm{~m} \mathrm{~s}^{-1}$, corresponding to an approximate $40 \%$ error in the magnitude of wind speed. The ratios of the estimated wind speeds vary up to 2, which implies that wind speed may be overestimated or underestimated significantly depending on the accuracy of the relative wind direction. As shown in Fig. 2(a) and 2(b), the differences in wind speeds according to the errors in wind direction tended to increase as the incidence angle and NRCS values increased. For an NRCS value of $-15 \mathrm{~dB}$ at an incidence angle of $45^{\circ}$, a wind direction difference of $20^{\circ}$, which is equivalent to the permitted limit of satellite scatterometry, yields wind speed differences up to $2.8 \mathrm{~m} \mathrm{~s}^{-1}$, which results in $16-30 \%$ error in the magnitude of the wind speed.

If wind-induced streaks are apparent on the image, wind direction can be directly estimated from the SAR image using the two-dimensional Fourier transform spectrum [10], [41]-[43], wavelet analysis [44]-[47], and local gradient [48]-[49]. However, these approaches are only valid for the cases when no ambient oceanic or atmospheric features are present, and a $180^{\circ}$ ambiguity still remains. Furthermore, an underdetermination problem associated with the sensitivity of single NRCS measurement to both wind speed and direction should be considered in the retrieved wind interpretation [50].

For general SAR wind retrievals, the wind direction information have been obtained from other external data, such as in-situ measurements, scatterometer wind data, or numerical model output data. Despite being available in most cases, their low spatial resolutions and inherent potential errors of aliasing due to their much coarser spatial resolutions compared to that of the SARs are regarded as insufficient for resolving smallscale structures in the surface wind field with subtle variations in wind direction [51]-[52].

Recently, methods based on polarimetric parameter analysis
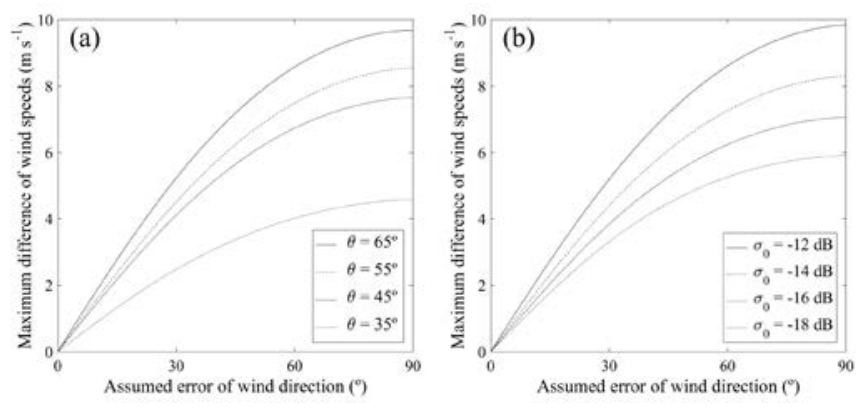

Fig. 2. Maximum differences in retrieved wind speeds from the CMOD5.N algorithm as a function of an error in wind direction. (a) for an NRCS value of $-15 \mathrm{~dB}$ and (b) at the incidence angle value of $45^{\circ}$.

were developed for the derivation of wind fields, including both speed and direction from the polarimetric SAR image alone [53]-[56]. Possible solutions of wind speed and direction are derived from the co- and/or cross-polarized ocean backscatters using combinations of the previous proposed methods. The ambiguities of the solutions are solved by the polarimetric components and their correlations, and hence wind vectors with a high-resolution can be derived from the SAR image itself without any external input data.

In this study, we focused on the spatial variation of SARderived wind vectors on the sea surface temperature (SST) front and investigated its mechanism using SAR data, in-situ measurements, and other satellite observations. The spatial variations of SST induce changes in the marine atmospheric boundary layer (MABL) or in the viscous properties of the sea surface which lead to variations in NRCS [57]-[64]. It has been reported that a decrease in water viscosity by cold water induces the dissipation of short gravity waves, which in turn leads to the attenuation of backscattering and hence a decrease in the magnitude of wind speeds [57]-[58].

On the other hand, several researches have pointed out that modification of wind field is attributed to the changes in MABL stability [59]-[64]. There have been attempts to demonstrate the role of atmospheric stability on wind variations quantitatively from the SAR images collocated with the thermal fronts of the Norwegian Coastal Current [59] and Gulf Stream [60]. Although the absolute magnitude of the predicted variations tended to be underestimated with uncertainty, the trends confirmed the influence of wind variations within the MABL on SAR imaging. Therefore, the relationship between SST gradients and variations of SAR-derived wind field with a highresolution provides an opportunity for identification of oceanic features associated with SST fronts [61]-[62] and investigation of the small-scale spatial variations related to air-sea interaction [63]-[64].

The objectives of this study are 1) to derive high-resolution sea surface wind fields from full-polarization SAR data, 2) to assess the accuracy of the derived winds by comparing it with in-situ measurements, and 3) to investigate the relationship between SST distribution and the spatial distinction of SAR wind vectors using satellite-observed SST by considering the influence of the MABL stability on wind fields. 

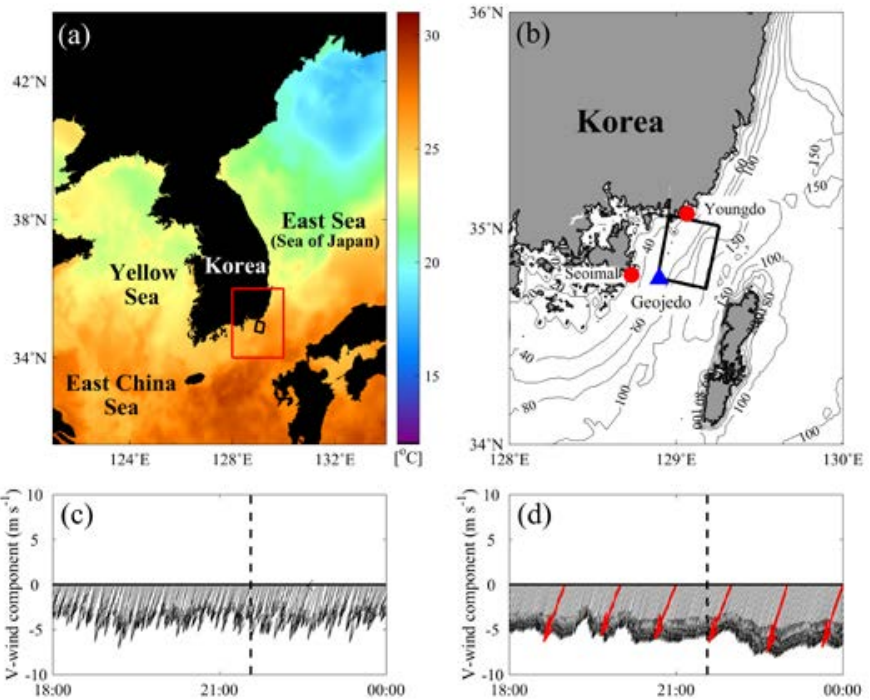

Fig. 3. (a) Distribution of daily mean sea surface temperature (SST, ${ }^{\circ} \mathrm{C}$ ) from the Multi-scale Ultra-high Resolution (MUR) SST data on August 23, 2008 in the seas around the Korean Peninsula, where the red box and black box indicate the study area and the location of the Radarsat-2 image, and (b) an enlarged image of the bathymetry contour in the study area, where the blue triangle and red circles indicate the locations of the Korean Meteorological Administration (KMA) buoy station (ID: Geojedo, $128.90^{\circ} \mathrm{E}, 34.76^{\circ} \mathrm{N}$ ) and Automatic Weather Stations (AWSs), respectively. Time-series of wind vectors from the AWS measurements at (c) Youngdo $\left(129.06^{\circ} \mathrm{E}, 35.06^{\circ} \mathrm{N}\right)$ and (d) Seoimal $\left(128.73^{\circ} \mathrm{E}\right.$, $34.78^{\circ} \mathrm{N}$ ), where dotted lines indicate the acquisition time of the Radarsat-2 image and red vectors indicate the hourly wind vectors from the in-situ buoy measurement.

\section{DATA}

\section{A. SAR Data}

To derive wind vectors from quad-polarization SAR data, a Radarsat-2 image of the area off the southern coast of Korea obtained in fine-quad mode was utilized (Fig. 3). The SAR data was obtained at C-band $(5.405 \mathrm{GHz}$ ) in quad-polarization states $(\mathrm{HH}+\mathrm{HV}+\mathrm{VH}+\mathrm{VV})$ with a swath of approximately $25 \mathrm{~km}$ and a nominal spatial resolution of $5.2 \mathrm{~m}$ (range) $\times 7.6 \mathrm{~m}$ (azimuth). Fig. 4 shows the distributions of the normalized radar cross section (NRCS) values at each polarization states. The mean values of the NRCSs were $-11.5 \mathrm{~dB}(\mathrm{HH}),-10.8 \mathrm{~dB}(\mathrm{VV})$, $-31.6 \mathrm{~dB}(\mathrm{HV})$, and $-31.5 \mathrm{~dB}(\mathrm{VH})$, respectively. The incidence angle of the image ranges from $24.6^{\circ}$ to $26.2^{\circ}$. The Radarsat-2 image was acquired at $21 \mathrm{~h} 33 \mathrm{~m}$ (UTC) on August 23,2008 , with the center of the image being located at $129.0^{\circ} \mathrm{E}$, $34.8^{\circ} \mathrm{N}$.

\section{B. In situ Measurement and Satellite SST Data}

For assessment of retrieved wind fields from the quad-pol SAR data, in-situ measurements obtained from the nearest Korean Meteorological Administration (KMA) meteorological buoy station with hourly intervals were used. The location of the KMA buoy station $\left(128.90^{\circ} \mathrm{E}, 34.76^{\circ} \mathrm{N}\right)$ is marked by the blue triangle in Fig. 3(b). As shown in Fig. 3(c) and 3(d), 1minute time-series of in-situ winds from the nearest ground-
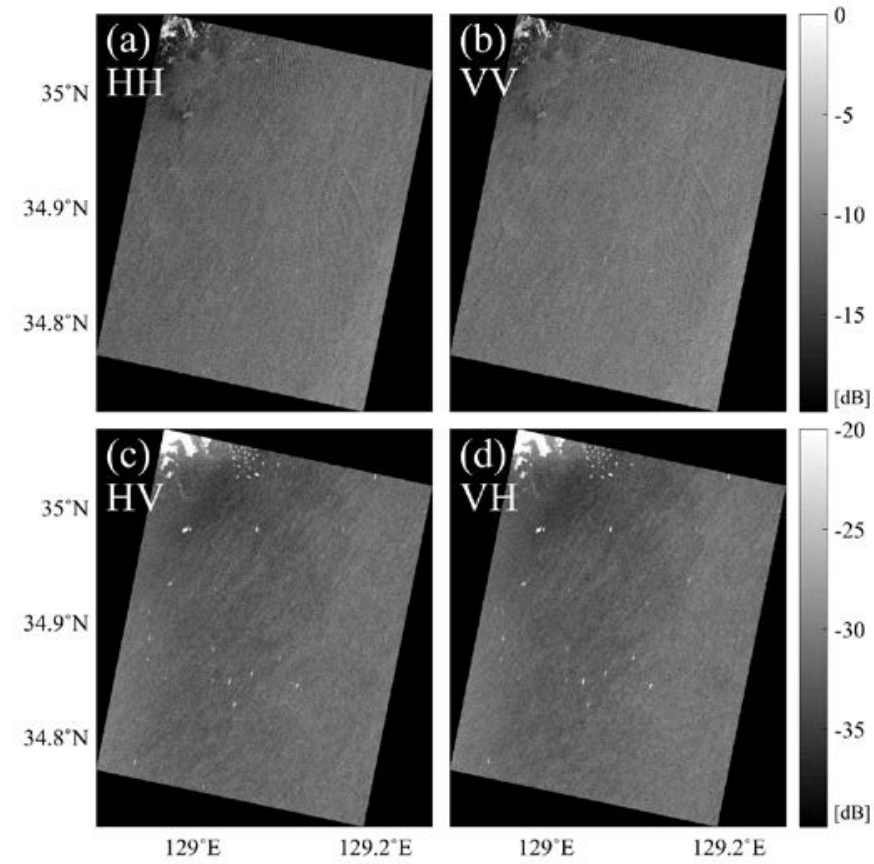

Fig. 4. Distributions of the normalized radar cross-section (dB) at (a) HH-, (b) VV-, (c) HV-, and (d) VH-polarization state.

based automatic weather stations (AWSs) of the KMA, which are marked by the red circles in Fig. 3(b), showed that consistent winds blew over hours at the study area. Since satellite-based wind speeds were referenced to a height of $10 \mathrm{~m}$, the wind measurements observed at $4.3 \mathrm{~m}$ were converted to a $10-\mathrm{m}$ neutral wind for the precise comparison by applying the Liu-Katsaros-Businger (LKB) model [65]-[66], which includes air-sea stability effects.

To investigate the spatial distribution of the SST, high resolution SST images from the National Oceanic and Atmospheric Administration (NOAA) Advanced Very High Resolution Radiometer (AVHRR) were utilized. The SSTs were derived from the AVHRR data of NOAA-18 through the Research Institute of Oceanography (RIO), Seoul National University (SNU) by applying a split window Multi-Channel SST (MCSST) algorithm [67]. The AVHRR SST retrieval accuracy is about $0.5^{\circ} \mathrm{C}$ [68].

\section{Model Data and Land Elevation Data}

The reanalysis wind data from the European Center for Medium-range Weather Forecasts (ECMWF) were utilized for comparison of the wind direction retrieval results. As the native spatial resolution of the reanalysis dataset is approximately 80 $\mathrm{km}$, which is inadequate for quantitative analysis of the coastal wind variations [69], we used the reanalysis wind data for qualitative comparison of a general spatial pattern of the retrieved wind field only. The time difference between the model winds and the SAR image was within 3 hours, while the time-series of in-situ winds showed a consistency of blowing wind over the study region. Additionally, air temperatures from the ECMWF reanalysis data were utilized for the analysis of the 


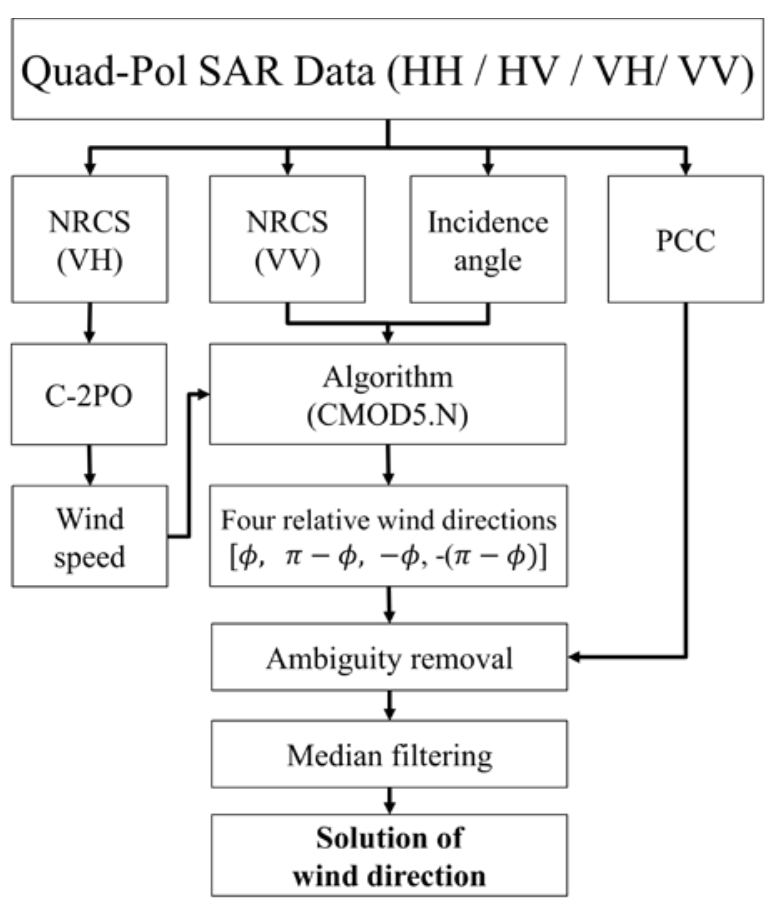

Fig. 5. Schematic flow chart of the wind retrieval from quad-polarization SAR data, where the acronyms indicate the normalized radar cross section (NRCS), polarization correlation coefficient (PCC), C-band cross-polarized ocean backscatter model (C-2PO), and C-band geophysical model function for the equivalent neutral wind (CMOD5.N), respectively.

spatial distinction of the wind field.

Global Digital Elevation Model (GDEM) data from Advanced Spaceborne Thermal Emission and Reflection Radiometer (ASTER) with a very high spatial resolution of 1 arc-second (approximately $30 \mathrm{~m}$ ) were used for the land masking. The ASTER GDEM data have been jointly generated and released by the Ministry of Economy, Trade, and Industry (METI) of Japan and by the United States National Aeronautics and Space Administration (NASA) since 2009. In this study, we used the most recent dataset updated in 2011.

\section{METHODS}

\section{A. Derivation of First-guess Wind Speed}

Fig. 5 shows a flow chart of the wind direction retrieval using quad-polarization SAR data. Prior to deriving the wind direction solutions, a first-guess wind speed, which is one of the input parameters for the wind direction retrieval, was derived. Among the C-band cross-polarization wind speed retrieval models [70]-[72], a C-band cross-polarized ocean backscatter model (C-2PO), which is independent of the incidence angle and wind direction, was applied to estimate a first-guess wind speed in this study. The C-2PO algorithm relates the $\mathrm{VH}$ polarized NRCS to the equivalent neutral wind speed at a height of $10 \mathrm{~m}$ as follows:

$$
\sigma_{V H}^{0}=0.580 U_{10}-35.652
$$

where $\sigma_{V H}^{0}$ and $U_{10}$ are VH-polarized NRCS values in $\mathrm{dB}$ and the wind speed at $10 \mathrm{~m}$ in height in meters per second,
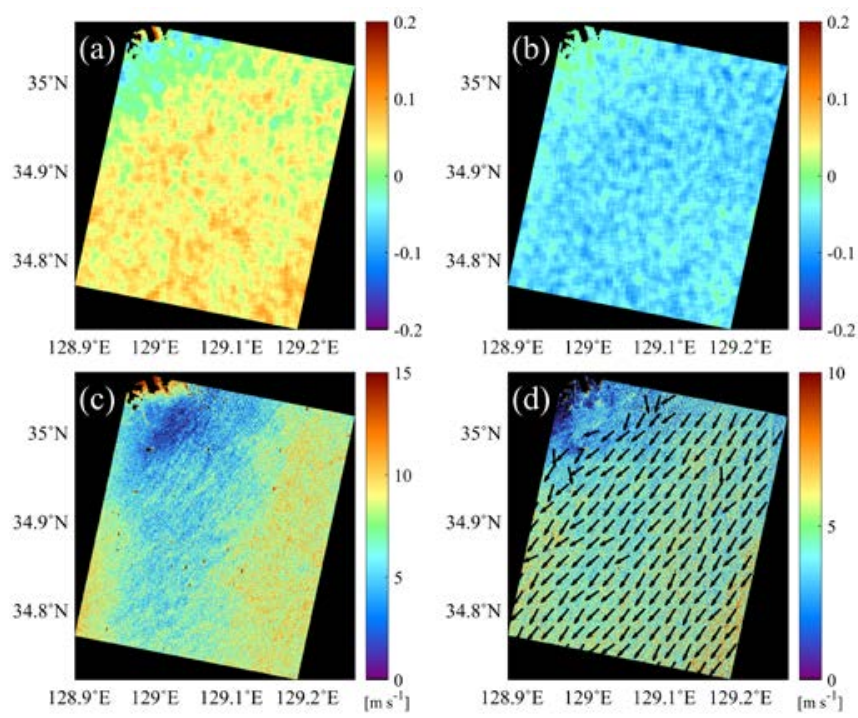

Fig. 6. (a) Real and (b) imaginary parts of the polarization correlation coefficients (PCC) from the Radarsat-2 image. Distributions of (c) wind speed $\left(\mathrm{m} \mathrm{s}^{-1}\right)$ from VH-polarized SAR data using the C-2PO algorithm and (d) the retrieved wind fields from the PCC and CMOD5.N algorithm after median filtering.

respectively [71]. It should be noted that this model function is valid only for the cross-polarized ocean backscatter above the noise equivalent sigma naught (NESZ) level. The fine quadpolarization Radarsat-2 data have a radiometric calibration error of less than $1 \mathrm{~dB}$ corresponding to a maximum difference of $1.72 \mathrm{~m} \mathrm{~s}^{-1}$ in retrieved wind speed, and NESZ of $-36.5 \pm 3$ $\mathrm{dB}$ [73]. It has been reported that the $\mathrm{C}-2 \mathrm{PO}$ shows a root mean square (RMS) error of $1.63 \mathrm{~m} \mathrm{~s}^{-1}$ and a bias of $0.01 \mathrm{~m} \mathrm{~s}^{-1}$ when compared with the in-situ buoy measurements [71].

Before applying the algorithm, the SAR data was preprocessed to extract the NRCS for each polarization state and incidence angle, along with ancillary information. The land areas were masked using the ASTER GDEM data. In addition, ship features having strong backscattering were detected from VH-polarized NRCSs by applying adaptive thresholding method [74]-[75] and then masked out. The remaining ocean pixels were averaged in a $20 \times 20$ moving window to reduce speckle noise. Using the wind speeds derived from the crosspolarized NRCS by the C-2PO algorithm, we calculated wind directions including four ambiguity solutions. Subsequently, wind speeds were recalculated using CMOD5.N algorithm from VV-polarized NRCS values and derived wind directions.

\section{B. Wind Direction Retrieval from Quad-polarization Data}

In general, the GMFs designed for co-polarized NRCSs have been widely used for the SAR wind retrieval. These model functions exhibit the relationship between co-polarized NRCS, wind speed, relative wind direction, and incidence angle. By using the co-polarized NRCSs (i.e., the VV-polarized NRCSs), incidence angles from the image, and derived wind speeds from the C-2PO as inputs to the GMFs, the solutions of wind directions at given values can be retrieved. In this study, the CMOD5.N algorithm was used among the C-band GMFs for 


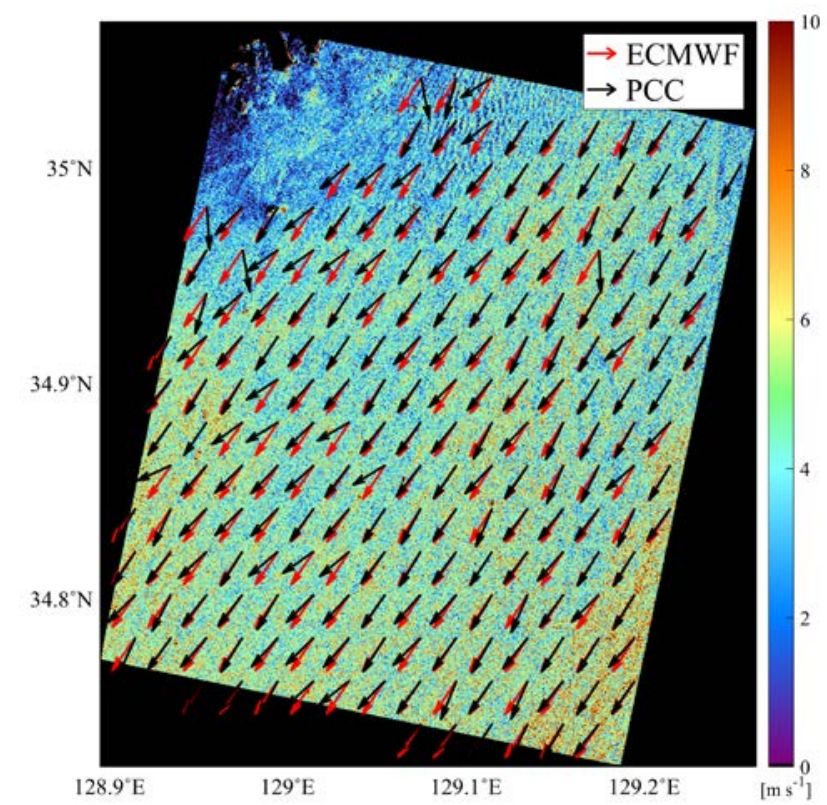

Fig. 7. Comparison of the retrieved wind vectors using wind directions derived from the ECMWF reanalysis wind data (red) and the polarization correlation coefficient method (black).

the co-polarized NRCS. Normally, the four solutions are found because of the directional symmetry to the relative wind direction.

To distinguish one true solution from the other three wind directions with ambiguity, polarimetric correlation coefficients (PCCs) between the VV- and VH- polarized scattering components were used. The correlation coefficient between VV- and HV-polarized channels is expressed as follows:

$$
\rho_{V V V H}=\frac{\left\langle S_{V V} \cdot S_{V H}^{*}\right\rangle}{\sqrt{\left\langle\left|S_{V V}\right|^{2}\right\rangle\left\langle\left|S_{V H}\right|^{2}\right\rangle}}
$$

where $S_{V V}$ and $S_{V H}$ indicate the scattering elements of the vertically transmitted and vertically received (VV) and horizontally received (VH) components, respectively. Since the real and imaginary parts of the PCC have odd symmetry with respect to relative wind direction, the ambiguities of the solutions can be removed according to the criteria [53].

To remove the remaining ambiguities in the spatial distribution of the retrieved wind field, median filtering with a window size of $100 \times 100$ was applied after the determination of the wind direction.

\section{RESULTS}

\section{A. Assessment of the Retrieved Wind Field}

Figs. 6(a) and 6(b) show the distributions of the PCCs from the Radarsat-2 quad-pol data. The PCCs were calculated by ensemble averaging in a moving window of size $1 \mathrm{~km} \times 1 \mathrm{~km}$. As shown, the positive (negative) values of the real (imaginary) parts were dominantly distributed in the study area. The mean and standard deviation (STD) values of the PCC components were 0.03 (mean) and 0.02 (STD) for the real part and -0.05
TABLE I

WIND SPEEDS AND DIRECTIONS FROM IN SITU MEASUREMENTS AND SAR WIND RETRIEVALS

\begin{tabular}{ccc}
\hline \hline & Wind speed $\left(\mathrm{m} \mathrm{s}^{-1}\right)$ & $\begin{array}{c}\text { Wind direction } \\
\text { (degree) }\end{array}$ \\
\hline Buoy & 9.9 & 217 \\
VH-pol (C-2PO) & 8.4 & - \\
VV-pol \\
(CMOD5.N with \\
ECMWF data) \\
Quad-pol (PCC)
\end{tabular}

(mean) and 0.01 (STD) for the imaginary part. Conversely, the prevailing uniform values near zero appeared in the upper left part of the image that is close to land. Considering the influence of land, the pixels within $3 \mathrm{~km}$ from the land area were excluded in the following wind direction retrieval.

With the PCCs, the wind speeds derived from VH-polarized NRCS using the C-2PO algorithm was input for the wind direction retrieval as a first-guess (Fig. 6(c)). When compared with the buoy measurement, the retrieved wind speed showed a difference of $1.5 \mathrm{~m} \mathrm{~s}^{-1}$, between $8.4 \mathrm{~m} \mathrm{~s}^{-1}$ for the crosspolarized SAR wind and $9.9 \mathrm{~m} \mathrm{~s}^{-1}$ for the buoy wind. Fig. 6(d) presents the distribution of the retrieved wind vector fields from the Radarsat-2 quad-pol data off the southern coast of Korea on August 23, 2008. The wind speeds in Fig. 6(d) were recalculated from the CMOD5.N algorithm with using the derived wind direction. The retrieved wind field illustrates a small-scale spatial variation at the coastal region. Overall, moderate northeasterly winds were apparent while northerly and easterly wind vectors partly appeared at the central parts of the study area.

For assessment of the retrieved wind vectors, we compared the results with the buoy measurement and those derived from the CMOD5.N algorithm using the ECMWF winds. As shown in Fig. 7, a comparison with the wind vectors from the ECMWF reanalysis data, which were interpolated into the resampling points same as those of the retrieved wind field, shows no great difference with the exception of some spatial variations. The wind speeds derived from the CMOD5.N algorithm using the ECMWF winds and PCC results indicated values of $7.9 \mathrm{~m} \mathrm{~s}^{-1}$ (ECMWF) and $8.1 \mathrm{~m} \mathrm{~s}^{-1}$ (PCC), respectively, at the nearest
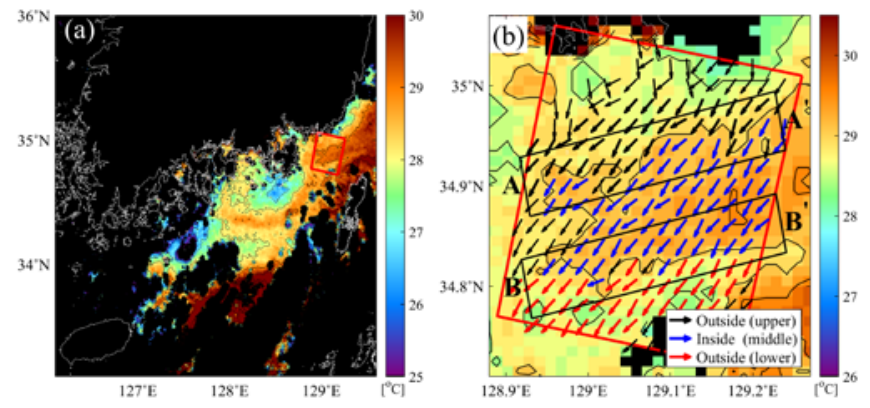

Fig. 8. (a) Distribution of sea surface temperature $\left({ }^{\circ} \mathrm{C}\right)$ from NOAA AVHRR data acquired at $04 \mathrm{~h} 47 \mathrm{~m}$ on August 23, 2008 and (b) an enlarged image at the location of the SAR image with the retrieved wind vectors. 


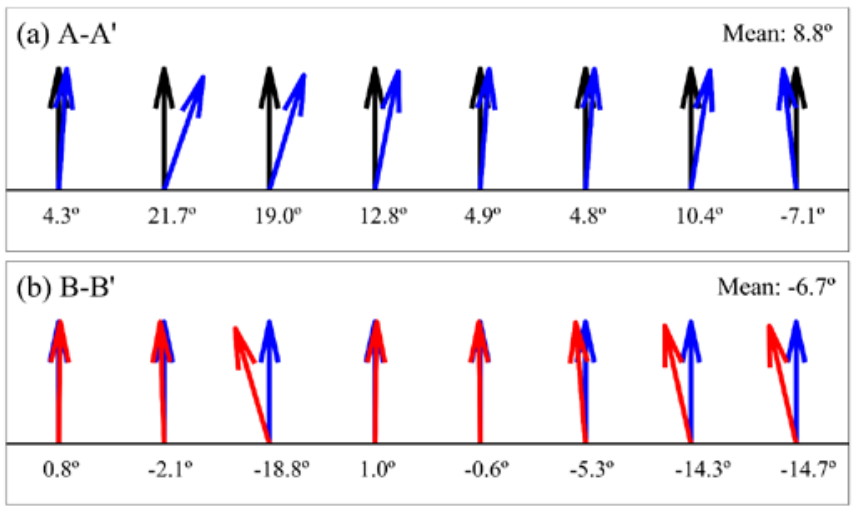

Fig. 9. Comparison of relative wind direction $\left(^{\circ}\right)$ between the wind vectors along the frontal regions (a) A-A' and (b) B-B' in Fig. 8b.

point to the buoy station. These were underestimated in comparison to the buoy measurement $\left(9.9 \mathrm{~m} \mathrm{~s}^{-1}\right)$ which has a time gap of about 27 minutes with the Radarsat-2 image acquisition. The wind direction derived using the PCC coincided well with the buoy measurements with a difference of only $8^{\circ}$, between $225^{\circ}$ for the SAR wind and $217^{\circ}$ for the buoy wind (Table I). Previous search demonstrated that RMS differences between the scatterometer and buoy data were generally within a range of $\pm 2 \mathrm{~m} \mathrm{~s}^{-1}$ for wind speed and $\pm 20^{\circ}$ for direction [76]-[78]. In case of the previous SAR-derived wind direction retrievals, it has been reported that RMS differences ranged over $30^{\circ}$ [79]-[80].

\section{B. Wind Direction Changes on the SST Front}

To investigate the spatial variation of the wind vectors, we analyzed the distributions of the SST at the study area. Figs. 8(a) and 8(b) show the spatial distribution of the SST off the southern coast of Korea from the NOAA AVHRR at $04 \mathrm{~h} 47 \mathrm{~m}$ (UTC) on August 23, 2008 and an enlarged image with the retrieved wind vectors in the study area. Except for inconsistently low winds at the upper part of the image near the land, the wind vectors tend to the southwestward across the SST front elongated along the middle part of the study area. Following the mean wind direction from northeast to southwest, we divided the wind vectors into three groups, which were outside and inside the SST frontal zone in the upper (black), middle (blue), and lower (red) regions.

Despite the consistent wind field distribution, significant changes in the wind direction appeared at the regions along the front. Figs. 9(a) and (b) illustrate the comparison of the relative wind directions of the wind vectors across the front A-A' and B-B' in Fig. 8(b). Pairs of wind vectors before and after crossing the front were sampled along the wind direction and then differences in the direction between those pairs were calculated. As shown in Fig. 9(a) and (b), two groups of the pairs present opposite tendencies of direction shift according to the SST variation. In the case of the front A-A', most wind vectors turn clockwise across the frontal region, and turn counterclockwise for the case of the front B-B'. The mean values of the wind direction change, based on a clockwise
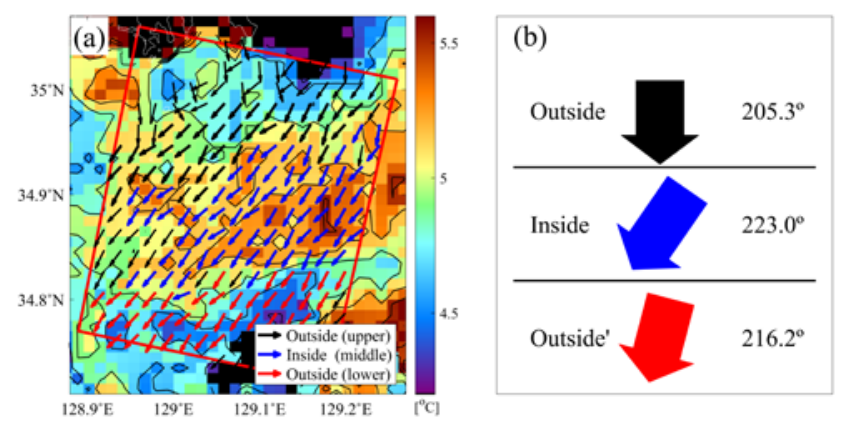

Fig. 10. (a) Distribution of temperature difference $\left({ }^{\circ} \mathrm{C}\right)$ between sea surface temperature and air temperature on August 23, 2008 and (b) mean wind directions at the regions outside and inside the SST frontal zone.

direction, were $8.8^{\circ}\left(\mathrm{A}-\mathrm{A}^{\prime}\right)$ and $-6.7^{\circ}$ (B-B'). This implies that apparent wind directions of the retrieved wind vectors tend to be shifted in a clockwise (counterclockwise) direction when wind vectors blow toward warmer (colder) regions.

\section{Stability Effect on the Changes in Wind Direction}

The retrieved wind vectors present significant changes in wind direction across the SST front. The mechanisms causing these particular variations were investigated. The pattern of wind direction changes seemed to be highly correlated with the modification of the veering angle induced by changes in atmospheric stability within the MABL. According to previous researchers, the near surface winds derived from MABL neutrality are affected strongly by the SST front through MABL modifications [8]-[9].

The MABL stability can be approximated by the air-sea temperature difference. Fig. 10(a) presents the distribution of temperature differences between the SST and air temperature $\left({ }^{\circ} \mathrm{C}\right)$ at the retrieved wind field region. While the region inside the SST front indicates a large air-sea temperature difference, regions outside the front indicate relatively small differences between the SST and air temperature. The mean wind directions of wind vectors in each region were $205.3^{\circ}$ (upper outside), $223.0^{\circ}$ (inside), and $216.2^{\circ}$ (lower outside). At the region inside the SST front with larger differences between SST and surface air temperature, the MABL instability increased. As MABL became more destabilized, the air-sea momentum more effectively transmitted, i.e., increased the wind stress, and decreased the veering angle of the surface winds [9]. It has been reported that the wind adjusts to a change in the stability of the MABL instantly within a small spatial scale less than $25 \mathrm{~km}$ [8].

Therefore, when referenced to the upwind as shown in Fig. 10(b), the blowing winds turned in a clockwise direction at the SST frontal zone and then in a counterclockwise direction analogous to an upwind direction. In this respect, it is inferred that the modification of the winds was mainly associated with the influence of the SST front on the MABL.

\section{DISCUSSION AND CONCLUSION}

In this study, we derived high-resolution wind vectors at the sub-km scale from full-polarization SAR data using the PCCbased method. Comparison of the SAR-derived wind directions 
with in-situ buoy wind measurements showed a small difference of less than $10^{\circ}$, which implied that the results of the retrieval satisfied an acceptable level of accuracy for the investigation of small-scale wind field variations.

While the scatterometer wind retrieval residual also revealed the evidence of local wind variability on the sub wind-vectorcell (WVC) scale [81], SAR-derived wind fields presented the detailed structure of the local wind variation. The retrieved wind field off the southern coast of Korea from the Radarsat-2 quad-polarization data showed distinct patterns of direction changes. The analysis of SAR-derived wind vectors with the coincident SST image may suggest that these spatial distinctions were associated with the existence of the SST front. Blowing over the SST frontal zone, the veering angles of the wind vectors decreased and were then restored. The pattern of wind direction changes fairly coincided with the distribution of the temperature differences between the SST and air temperature, which indirectly indicated MABL stability. Therefore, it is inferred that the changes in MABL stability dominantly induced the variation of the SAR wind vectors on the SST front.

Although the results reveal the applicability of highresolution wind field from full-polarization SAR data, further manipulation of the wind direction retrievals should be taken. For an NRCS value of $-10 \mathrm{~dB}$ at an incidence angle of $45^{\circ}$, a wind speed difference of $1.63 \mathrm{~m} \mathrm{~s}^{-1}$, corresponding to an RMS error of the cross-polarized ocean backscatter model, yields an RMS error of $8.2^{\circ}$ in the wind direction retrieval. For quantitative analysis of the wind field variation, the development of techniques to reduce the inherent systematic errors in the wind retrieval should be continued. Additionally, there is need for further work to verify the sensitivity of the SAR-derived winds to variations both in the longitudinal and transverse winds [82]. Except the ASCAT scatterometry, most ocean wind sensing techniques still do not generally provide it.

In this study, we focused on the directional changes of wind vectors in the sub-kilometer scale. The interaction of the derivatives in the SST and wind stress fields demonstrated that changes in wind speed and direction occur, depending on the orientation of the mean flow and SST gradients [83]. The study of such effects requires an acquisition of sufficient multipolarization SAR images and ancillary dataset and will be the subject of future work. It is very promising, as more satellite SAR operation programs, e.g., the RADARSAT Constellation Mission, will provide dual-polarized data or compact polarimetric data which can be transformed to quad-polarized data.

\section{ACKNOWLEDGMENT}

The Radarsat-2 data were supported by the project titled "Development of Management Technology for HNS Accident”, funded by the Ministry of Oceans and Fisheries, Korea. Data processing of SST was partly supported by the project titled "Deep Water Circulation and Material Cycling in the EAST Sea”, funded by the Ministry of Oceans and Fisheries, Korea. The views, opinions, and findings contained in this report are those of the authors and should not be construed as an official NOAA or U.S. Government position, policy, or decision.

\section{REFERENCES}

[1] W. Tang, W. T. Liu, and B. W. Stiles, "Evaluation of high-resolution ocean surface vector winds neasured by QuikSCAT scatterometer in coastal regions," IEEE Trans. Geosci. Remote Sens., vol. 42, no. 8, pp. 1762-1769, Aug. 2004.

[2] Y. Quilfen, B. Chapron, T. Elfouhaily, K. Katsaros, and J. Tournadre, "Observation of tropical cyclones by high-resolution scatterometry," $J$. Geophys. Res., vol. 103, no. C4, pp. 7767-7786, Apr. 1998.

[3] M. A. Bourassa, L. Zamudio, and J. J. O’Brien, "Noninertial flow in NSCAT observations of Tehuantepec winds,” J. Geophys. Res., vol. 104, no. C5, pp. 11311-11319, 1999.

[4] P. C. Chu, S. Lu, and W. T. Liu, "Uncertainty of the South China Sea prediction using NSCAT and NCEP winds during tropical storm Ernie 1996,” J. Geophys. Res., vol. 104, no. C5, pp. 11273-11289, 1999

[5] R. F. Milliff, W. G. Large, J. Morzel, G. Danabasoglu, and T. M. Chin, "Ocean general circulation model sensitivity to forcing from scatterometer winds,” J. Geophys. Res., vol. 104, no. C5, pp. 1133711358, 1999.

[6] W. T. Liu, X. Xie, P. S. Polito, S. Xie, and H. Hashizume, “Atmosphere manifestation of tropical instability waves observed by QuikSCAT and Tropical Rain Measuring Missions,” Geophys. Res. Lett., vol. 27, no.16, pp. 2545-2548, 2000.

[7] K. B. Katsaros, E. B. Forde, P. Chang, and W. T. Liu, "QuikSCAT facilitates early identification of tropical depressions in 1999 hurricane season,” Geophys. Res. Lett., 28, no. 6, pp. 1043-1046, 2001.

[8] K.-A. Park and P. C. Cornillon, "Stability-induced modification of sea surface winds over Gulf Stream rings, Geophys. Res. Lett., vol. 29, no. 24, pp. 64-1-64-4, 2002.

[9] K.-A. Park, P. Cornillon, and D. L. Codiga, "Modification of surface winds near ocean fronts: Effects of Gulf Stream rings on scatterometer (QuikSCAT, NSCAT) wind observations,” J. Geophys. Res., vol. 111, no. C03021, pp. 1-19, 2006.

[10] C. Wackerman, C. Rufenach, R. Shuchman, J. Johannessen, and K. Davidson, "Wind vector retrieval using ERS-1 synthetic aperture radar imagery,” IEEE Trans. Geosci. Remote Sens., vol. 34, no. 6, pp. 13431352, Nov. 1996.

[11] V. Kerbaol, B. Chapron, and P. Queffeulou, "Analysis of the wind field during the Vendée Globe race: A kinematic SAR wind speed algorithm," Earth Obs. Q., vol. 59, pp. 16-19, 1998.

[12] D. Vandemark, P. W. Vachon, and B. Chapron, "Assessment of ERS-1 SAR wind speed estimates using an airborne altimeter," Earth Obs. Q., vol. 59, pp. 5-8, 1998.

[13] S. Lehner, J. Schulz-Stellenfleth, B. Schattler, H. Breit, and J. Horstmann, "Wind and wave measurements using complex ERS-2 SAR wave mode data," IEEE Trans. Geosci. Remote Sens., vol. 38, no. 5, pp. 2246-2257, Sep. 2000.

[14] K. S. Friedman, T. D. Sikora, W. G. Pichel, P. Clemente-Colón, and G. Hufford, "Using spaceborne synthetic aperture radar to improve marine surface analyses,” Weather Forecast., vol. 16, pp. 270-276, 2001.

[15] F. M. Monaldo, D. R. Thompson, R. C. Beal, W. G. Pichel, and P. Clemente-Colon, P., "Comparison of SAR-derived wind speed with model predictions and ocean buoy measurements," IEEE Trans. Geosci. Remote Sens., vol. 39, no. 12, pp. 2587-2600, Dec. 2002.

[16] J. Horstmann, D. R. Thompson, F. Monaldo, S. Iris, and H. C. Graber, "Can synthetic aperture radars be used to estimate hurricane force winds?" Geophys. Res. Lett., vol. 32, no. 22, p. L22801, 2005. DOI: 10.1029/2005GL023992.

[17] T. Shimada, "Structures and seasonal variations of surface winds blowing through the Tsushima strait," J. Appl. Meteor. Climatol., vol. 49, pp. 1714-1727, 2010.

[18] O. Isoguchi, M. Shimada, and H. Kawamura, "Characteristics of ocean surface winds in the Lee of an isolated island observed by synthetic aperture radar," Mon. Weather Rev., vol. 139, no. 6, pp. 1744-1761, 2011.

[19] A. A. Mouche, F. Collard, B. Chapron, K.-F. Dagestad, G. Guitton, J. A. Johannessen, V. Kerbaol, and M. W. Hansen, "On the use of Doppler shift for sea surface wind retrieval From SAR," IEEE Trans. Geosci. Remote Sens., vol. 50, no. 7, pp. 2901-2909, Jul. 2012.

[20] T.-S. Kim, K.-A. Park, X. Li, and S. Hong, "SAR-derived wind fields at the coastal region in the East/Japan Sea and relation to coastal upwelling," Int. J. Remote Sens., vol. 35, nos. 11-12, pp. 3947-3965, 2014. 
[21] E. Korsbakken, J. A. Johannessen, and O. M. Johannessen, “Coastal wind field retrievals from ERS SAR images,” in Proc. IEEE Int. Geosci. Remote Sens., 1997, pp. 1153-1155.

[22] H. Kawamura, T. Shimada, M. Shimada, A. Kortcheva, and I. Watabe, "L-band SAR wind-retrieval model function and its application for studies of coastal surface winds and wind waves,” in Proc. IEEE Int. Geosci. Remote Sens., 2002, pp. 1884-1886, 2002.

[23] J. Choisnard, M. Bernier, and G. Lafrance, "RADARSAT-1 SAR scenes for wind power mapping in coastal area: Gulf of St-Lawrence case," in Proc. IEEE Int. Geosci. Remote Sens., 2003, pp. 2700-2702.

[24] W. M. Moon, G. Staples, D.-J. Kim, S.-E. Park, and K.-A. Park, "RADARSAT-2 and coastal applications: Surface wind, waterline, and intertidal flat roughness," Proc. IEEE, vol. 98, no. 5, pp. 800-815, May 2010.

[25] G. S. Young, T. D. Sikora, N. S. Winstead, "Inferring marine atmospheric boundary layer properties from spectral characteristics of satellite-borne SAR imagery," Mon. Weather Rev., vol. 128, pp. 1506-1520, 2000.

[26] X. Li, W. G. Pichel, M. He, S. Y. Wu, K. S. Friedman, P. Clemente-Colón and C. Zhao, "Observation of hurricane-generated ocean swell refraction at the Gulf Stream north wall with the RADARSAT-1 synthetic aperture radar,” IEEE Trans. Geosci. Remote Sens., vol. 40, no. 10, pp. 2131-2142, 2002.

[27] X. Li, C. Dong, P. Clemente-Colón, W. G. Pichel, and K. S. Friedman, "Synthetic aperture radar observation of the sea surface imprints of upstream atmospheric solitons generated by flow impeded by an island," J. Geophys. Res., vol. 109, no. C2, p. C02016, 2004, DOI: 10.1029/2003JC002168.

[28] X. Li, W. Zheng, W. G. Pichel, C.-Z. Zou, and P. Clemente-Colón, “Coastal katabatic winds imaged by SAR,” Geophys. Res. Lett., vol. 34, no. 3, p. L03804, 2007, DOI:10.1029/2006GL028055.

[29] X. Li, J. A. Zhang, X. Yang, W. G. Pichel, M. De Maria, D. Long, and Z. $\mathrm{Li}$, "Tropical cyclone morphology from spaceborne synthetic aperture radar,” Bull. Amer. Meteorol. Soc., vol. 94, pp. 215-230, 2013.

[30] X. Li, W. Zheng, X. Yang, J. A. Zhang, W. G. Pichel, and Z. Li, "Coexistence of atmospheric gravity waves and boundary layer rolls observed by SAR,” J. Atmos. Sci., vol. 70, no. 11, pp. 3448-3459, 2013.

[31] X. Li, W. Zheng, X. Yang, Z. Li, and W. G. Pichel, "Sea surface imprints of coastal mountain lee waves imaged by synthetic aperture radar," J. Geophys. Res., vol. 116, no. C2, p. C02014, 2011, DOI: 10.1029/2010JC006643.

[32] B. R. Furevik and H. A. Espedal, "Wind energy mapping using synthetic aperture radar," Can. J. Remote Sens., vol. 28, no. 2, pp. 196-204, 2002.

[33] C. B. Hasager, E. Dellwik, M. Nielsen, and B. Furevik, "Validation of ERS-2 SAR offshore wind-speed maps in the North Sea,” Int. J. Remote Sens., 25, 3817-3841, 2004.

[34] M. B. Christiansen, W. Koch, J. Horstmann, C. B. Hasager, and M. Nielsen, "Wind resource assessment from C-band SAR," Remote Sens. Environ., vol. 105, no. 1, pp. 68-81, 2006.

[35] F. M. Monaldo, X. Li, W. G. Pichel, and C. R. Jackson, "Ocean wind speed climatology from spaceborne SAR imagery,” Bull. Am. Meteorol. Soc., vol. 95, no. 4, pp. 565-569, 2014.

[36] C. B. Hasager, A. Mouche, M. Badger, F. Bingöl, I. Karagali, T. Driesenaar, A. Stoffelen, A. Peña, and N. Longépé, "Offshore wind climatology based on synergetic use of Envisat ASAR, ASCAT and QuikSCAT," Remote Sens. Environ., vol. 156, pp. 247-263, 2015.

[37] A. Stoffelen and D. Anderson, "Scatterometer data interpretation: Estimation and validation of the transfer function CMOD4," J. Geophys. Res., vol. 102, no. C3, pp. 5767-5780, 1997.

[38] IFREMER-CERSAT, "Off-line wind scatterometer ERS products: user manual,” Plouzane, France, Tech. Rep. C2-MUT-W-01-IF, 1999.

[39] H. Hersbach, A. Stoffelen, and S. De Haan, "An improved C-band scatterometer ocean geophysical model function: CMOD5,” J. Geophys. Res., vol. 110, no. C3, p. C03006, 2007, DOI:10.1029/2006JC003743.

[40] H. Hersbach, "Comparison of C-band scatterometer CMOD5.N equivalent neutral winds with ECMWF,” J. Atmos. Ocean. Technol., vol. 27, no. 4, pp. 721-736, Apr. 2010.

[41] F. Fetterer, D. Gineris, and C. C. Wackerman, "Validating a scatterometer wind algorithm for ERS-1 SAR,” IEEE Trans. Geosci. Remote Sens., vol. 36, no. 2, pp. 479-492, 1998.

[42] S. Lehner, J. Horstmann, W. Koch, and W. Rosenthal, "Mesoscale wind measurements using recalibrated ERS SAR images,” J. Geophys. Res. C: Oceans, vol. 103, no. 4, pp. 7847-7856, 1998.

[43] P. Vachon, and F. Dobson, "Wind retrieval from RADARSAT SAR images: selection of a suitable C-band $\mathrm{HH}$ polarization wind retrieval model," Can. J. Remote Sens., vol. 26, no. 4, pp. 306-313, 2000.
[44] Y. Du, P. W. Vachon, and J. Wolfe, "Wind direction estimation from SAR images of the ocean using wavelet analysis," Can. J. Remote Sens., vol. 28, no. 3, pp. 498-509, Jun. 2002.

[45] N. Fichaux and T. Ranchin, 2002. "Combined extraction of high spatial resolution wind speed and wind direction from SAR images: A new approach using wavelet transform,” Can. J. Remote Sens., vol. 28, no. 3, pp. 510-516, 2002.

[46] S. Zecchetto and F. De Biasio, "A Wavelet-based technique for sea wind extraction from SAR images," IEEE Trans. Geosci. Remote Sens., vol. 46, no. 10, 2983-2989, Oct. 2008.

[47] G. C. Leite, D. M. Ushizima, F. N. S. Medeiros, and G. G. de Lima, "Wavelet Analysis for Wind Fields Estimation," Sensors, vol. 10, pp. 5994-6016, 2010

[48] W. Koch, "Directional analysis of SAR images aiming at wind direction," IEEE Trans. Geosci. Remote Sens., vol. 42, no. 4, pp. 702-710, Apr. 2004.

[49] F. M. Rana, M. Adamo, G. Pasquariello, G. De Carolis, and S. Morelli, "LG-Mod: A modified local gradient (LG) method to retrieve SAR sea surface wind directions in marine coastal areas," J. Sensors, vol. 2016, p. 9565208, 2016, DOI: 10.1155/2016/9565208.

[50] M. Portabella, A. Stoffelen, J. A. Johannessen, "Toward an optimal inversion method for SAR wind retrieval,” J. Geophys. Res., vol. 107, no. C8, pp. 1-1-1-13, 2002, DOI:10.1029/2001JC000925.

[51] A. Stoffelen, "Toward the true near-surface wind speed: Error modeling and calibration using triple collocation,” J. Geophys. Res., vol. 103, no. C4, pp. 7755-7766, 1998, DOI:10.1029/97JC03180.

[52] J. Vogelzang, A. Stoffelen, A. Verhoef, J. Figa-Saldana, "On the quality of high-resolution scatterometer winds,” J. Geophys. Res., vol. 116, no. C10033, pp. C10033-1-C10033-1-14, 2011, DOI:10.1029/2010JC006640.

[53] B. Zhang, W. Perrie, P. W. Vachon, X. Li, W. G. Pichel, J. Guo, and Y. He, 2012. "Ocean vector winds retrieval from C-band fully polarimetric SAR measurements,” IEEE Trans. Geosci. Remote Sens., vol. 50, no. 11, pp. 4252-4261, Nov. 2012.

[54] Y. Zhang, X. Jiang, Q. Song, M. Lin, and X. Xie, "Coastal wind field retrieval from polarimetric synthetic aperture radar,” Acta Oceanol. Sin., vol. 33, no. 5, pp. 54-61, 2014.

[55] T. Ratsimbazafy and M. Bernier, "Wind direction ambiguity removal using RADARSAT-2 polarimetric SAR images," Can. J. Remote Sens., vol. 41, no. 4, pp. 249-261, 2015.

[56] B. Zhang, X. Li, W. Perrie, and Y. He, 2015, "Synergistic measurements of ocean winds and waves from SAR,” J. Geophys. Res. Oceans, vol. 120, no. 9, pp. 6164-6184, 2015.

[57] D. E. Weissman, "Dependence of the microwave radar cross section on ocean surface variables: Comparison of measurements and theory using data from the frontal air-sea interaction experiment,” J. Geophys. Res., vol. 95, no. C3, pp. 3387-3398, 1990.

[58] Q. Zheng, X.-H. Yan, V. Klemas, N. E. Huang, J.-Y. Pan., and Y.-I. Yuan, "Laboratory measurements of the effects of viscosity on short water wave spectra and implication for radar remote sensing of the ocean surface," Chin. J. Oceanol. Limn., vol. 13, no. 3, pp. 193-205, 1995.

[59] J. A. Johannessen, R. A. Shuchman, G. Digranes, D. R. Lyzenga, C. Wackerman, M. Johannessen, and P. W. Vachon, "Coastal ocean fronts and eddies imaged with ERS-1 synthetic aperture radar.” J. Geophys. Res., vol. 101, no. C3, pp. 6651-6667, 1996.

[60] R. C. Beal, V. N. Kudryavtsev, D. R. Thompson, S. A. Grodsky, D. G. Tilley, V. A. Dulov, and H. C. Graber, "The influence of the marine atmospheric boundary layer on ERS 1 synthetic aperture radar imagery of the Gulf Stream,” J. Geophys. Res., vol. 102, no. C3, pp. 5799-5814, 1997, DOI: 10.1029/96JC03109.

[61] T. Xie, W. Perrie, and W. Chen, "Gulf Stream thermal fronts detected by synthetic aperture radar," Geophys. Res. Lett., vol. 37, no. L06601, pp. L06601-1- L06601-5, 2010, DOI:10.1029/2009GL041972.

[62] H. Kuang, W. Perrie, T. Xie, B. Zhang, and W. Chen, "Retrievals of sea surface temperature fronts from SAR imagery," Geophys. Res. Lett., vol. 39, no. L10607, pp. L10607-1-L10607-7, 2012, DOI:10.1029/2012GL051288.

[63] P. Clemente-Colón and X.-H. Yan, 1999. "Observations of east coast upwelling conditions in synthetic aperture radar imagery." IEEE Trans. Geosci. Remote Sens., vol. 37, no. 5, pp. 2239-2248, 1999.

[64] T.-S. Kim, K.-A., Park, X. Li, and S. Hong, "SAR-derived wind fields at the coastal region in the East/Japan Sea and relation to coastal upwelling," Int. J. Remote Sens., vol. 35, nos. 11-12, 2014, DOI: 10.1080/01431161.2014.916438. 
[65] W. T. Liu, K. B. Katsaros, and J. A. Businger, "Bulk parameterization of air-sea exchanges of heat and water vapor including the molecular constraints at the interface," J. Atmos. Sci., vol. 36, pp. 1722-1735, 1979.

[66] W. T. Liu and W. Tang, "Equivalent Neutral Wind," NASA Jet Propulsion Laboratory, Pasadena, CA, USA, Tech. Rep. 96-17, 1996.

[67] E. P. McClain, W. G. Pichel, and C. C. Walton, "Comparative performance of AVHRR-based multichannel sea surface temperatures,” J. Geophys. Res., vol. 90, no. C6, pp. 11587-11601, 1985.

[68] X. Li, W. Pichel, P. Clemente-Colón, V. Krasnopolsky, and J. Sapper, "Validation of coastal sea and lake surface temperature measurements derived from NOAA/AVHRR data,” Int. J. Remote Sens., vol. 22, no. 7, pp. 1285-1303, 2001.

[69] I. L. Wijnant, G. J. Marseille, A. Stoffelen, H. W. van den Brink, and A. Stepek, "Validation of KNW atlas with scatterometer winds (Phase 3 of KNW project),” KNMI, De Bilt, Netherlands, Tech. Rep. TR-353, 2015.

[70] P. W. Vachon and J. Wolfe, "C-band cross-polarization wind speed retrieval,” IEEE Trans. Geosci. Remote Sens., vol. 8, no. 3, pp. 456-459, May 2011, DOI:10.1109/LGRS.2010.2085417.

[71] B. Zhang and W. Perrie, "Cross-polarized synthetic aperture radar: A potential measurement technique for hurricanes," Bull. Amer. Meteorol. Soc., vol. 93, no. 4, pp. 531-541, Apr. 2012.

[72] van Zadelhoff, G.-J., A. Stoffelen, P. W. Vachon, J. Wolfe, J. Horstmann, and M. Belmonte Rivas, "Retrieving hurricane wind speeds using crosspolarization C-band measurements,” Atmos. Meas. Tech., vol. 7, pp. 437449, 2014, DOI:10.5194/amt-7-437-2014

[73] MacDonald Dettwiler and Associates Ltd., "RADARSAT-2 product description,” MDA, Richmond, Canada, Tech. Rep. RN-SP-52-1238, 2016.

[74] P. W. Vachon, S. J. Thomas, J. A. Cranton, C. Bjerkelund, F. W. Dobson, and R. B. Olsen, "Monitoring the coastal zone with the RADARSAT satellite,” In Proceedings of Oceanology Int., vol. 98, pp. 29-38, 1998.

[75] A. H. S. Solberg, G. Storvik, R. Solberg, and E. Volden, "Automatic detection of oil spills in ERS SAR images,” IEEE Trans. Geosci. Remote Sens., vol. 37, no. 4, pp. 1916-1924. 1999, DOI: 10.1109/36.774704.

[76] M. H. Freilich and R. S. Dunbar, "The accuracy of the NSCAT vector winds: Comparisons with National Data Buoy Center buoys,” J. Geophys. Res., vol. 104, no. C5, pp. 11231- 11246, 1999, DOI:10.1029/1998JC900091.

[77] N. Ebuchi, H. C. Graber, and M. J. Caruso, "Evaluation of wind vectors observed by QuikSCAT/SeaWinds using ocean buoy data,” J. Atmos. Oceanic Technol., vol. 19, pp. 2049-2062, 2002, DOI:10.1175/15200426(2002)019<2049:EOWVOB >2.0.CO;2.

[78] M. H. Pickett, W. Tang, L. K. Rosenfeld, and C. H.Wash, "QuikSCAT satellite comparison with nearshore buoy wind data off the U.S. west coast,” J. Atmos. Oceanic Technol., vol. 20, pp. 1869-1879, 2003, DOI:10.1175/1520-0426(2003)020<1869:QSCWNB>2.0.CO;2.

[79] F. Fetterer, D. Gineris, and C. Wackerman, "Validating a scatterometer wind algorithm for ERS-1 SAR,” IEEE Trans. Geosci. Remote Sens., vol. 36, no. 2, pp. 479-492, Mar. 1998.

[80] D.-J. Kim, and W. I. Moon, "Estimation of sea surface wind vector using RADARSAT data,” Remote Sens. Environ., vol. 80, pp. 55-64, 2002.

[81] W. Lin, M. Portabella, A. Stoffelen, and A. Turiel, "ASCAT wind quality control near rain,” IEEE Trans. Geosci. Remote Sens., vol. 53, no. 8, pp. 1-13, 2015, DOI: 10.1109/TGRS.2015.2392372.

[82] A. Stoffelen and M. Portabella, M., "On Bayesian scatterometer wind inversion,” IEEE Trans. Geosci. Remote Sens., vol. 44, pp. 1523-1533, 2006, DOI: 10.1109/TGRS.2005.862502.

[83] R. M. Samelson, E. D. Skyllingstad, D. B. Chelton, S. K. Esbensen, L. W. O'Neill, and N. Thum, "On the coupling of wind stress and sea surface temperature,” J. Climate, vol. 19, pp. 1557-1566, Apr. 2006, DOI: 10.1175/JCLI3682.1.

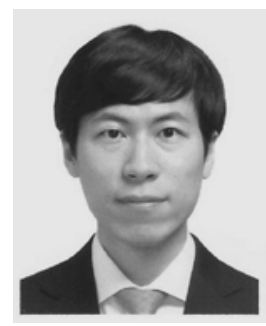

Tae-Sung Kim received the B.S. degree in earth system science, and the M.S. and $\mathrm{Ph} . \mathrm{D}$. degrees in satellite oceanography from Seoul National University, Seoul, South Korea, in 2007, 2010, and 2016, respectively. He is currently a Postdoctoral Researcher with Seoul National University. His research interests include the study of oceanic phenomena in the coastal region using synthetic aperture radar (SAR) data, as well as SAR oceanic application for oil spill detection and oceanic parameter extractions. He received the Len Curtis Award of International Journal of Remote Sensing, Remote Sensing \& Photogrammetry Society’s Annual Conference in U.K., in 2015.

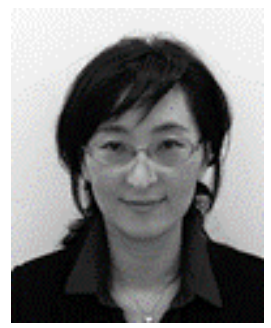

Kyung-Ae Park received the B.S. degree in earth science education, the M.S. degree in physical oceanography, and the Ph.D. degree in satellite oceanography from the Seoul National University, Seoul, South Korea, in 1987, 1989, and 1996, respectively. Since 2007, she has been a Professor at the Department of Earth Science Education, Seoul National University, Seoul, South Korea. Her research interests include the study of physical processes and ocean dynamics of mesoscale oceanic phenomena using multisatellite data and oceanic in situ measurements at regional scales in the East/Japan Sea and the marginal seas of the northwest Pacific Ocean. She has long utilized a variety of satellite remote sensing techniques (sea surface temperature, near-surface wind, chlorophyll-a concentration, suspended sediment, wave height, sea level, and SAR) in her researches and applied them for physical oceanographic applications including air-sea interaction and its linkage to climate change. She received the Best Paper Award of Korean Federation of Science and Technology Societies in 2012, the Best Paper Award of Korean Society of Remote Sensing in 2013, and the Len Curtis Award of International Journal of Remote Sensing, Remote Sensing \& Photogrammetry Society's Annual Conference in U.K., in 2015.

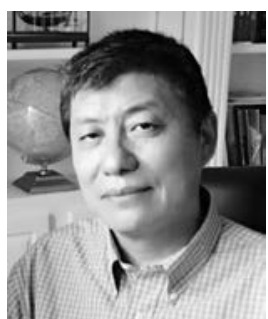

Xiaofeng Li (M'00-SM'11) received the B.S. degree in optical engineering from Zhejiang University, Hangzhou, China, in 1985; the M.S. degree in physical oceanography from the First Institute of Oceanography, State Oceanic Administration, Qingdao, China, in 1992; and the Ph.D. degree in physical oceanography from North Carolina State University, Raleigh, NC, USA, in 1997. During the M.S. program, he completed the graduate course work in the Department of Physics, University of Science and Technology of China, Hefei, China.

Since 1997, he has been with the National Environmental Satellite, Data, and Information Service (NESDIS), NOAA, College Park, MD, USA. He is involved in developing many operational satellite ocean remote sensing products at NESDIS. $\mathrm{He}$ is an author of more than 100 peer-reviewed publications. His research interests include remote sensing observation and theoretical/numerical model studies of various types of oceanic and atmospheric phenomena, satellite image processing, ocean surface oil spill and target detection/classification with multipolarization SAR, and development of sea surface temperature algorithms. 
Dr. Li currently serves as the Senior Associate Editor for Remote Sensing and the Associate Editor for the International Journal of Remote Sensing and an Editorial Board Member for the International Journal of Digital Earth. He was the guest editor of the International Journal of Remote Sensing special issue on "Remote Sensing of the China Seas (2014)", Maritime Oil Spill Response (Elsevier, 2015), and the IEEE JSTARS special issue on "Remote Sensing of the World Oceans (2016)". He was appointed as an "Overseas Expert" by the Chinese Academy of Sciences in 2014 and won the NOAA/NESDIS Center for Satellite Applications and Research (STAR) the Individual Award for Science and the Len Curtis Award from Remote Sensing and Photogrammetry Society in 2015.

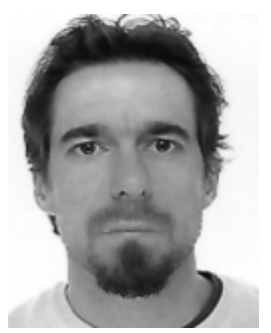

Alexis Mouche is a Research Scientist at IFREMER. He received a Ph.D. in ocean remote sensing in 2005. He joined the Laboratoire d'Océanographie Spatiale at IFREMER in 2006 for a 2 years postdoctoral position granted by the French spatial agency (CNES) to work on the ocean dynamics as observed at high resolution. From 2008 to 2013, he worked as research engineer for BOOST and then CLS (CNES and IFREMER subsidiary) to develop algorithms for wind, waves and current measurements with synthetic aperture radar (SAR) from space. He has now a permanent position at IFREMER since January 2014. His principal field of interest is the interactions of electromagnetic and oceanic waves for ocean remote sensing applications. He is presently involved in the CAL/VAL activities for European Sentinel-1A SAR where he is in charge of the coordination of scientific activities to be conducted by expert support laboratories for ocean level-2 products. He is also involved in the preparation of the CAL/VAL activities for the Chinese-French CFOSAT satellite and participate to the preparation of the IFREMER ocean waves products from level 2 to level 4.

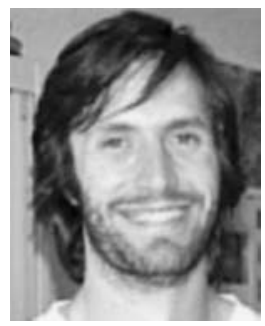

Bertrand Chapron was born in Paris, France, in 1962. He received the B.Eng. degree in physic from the Institut National Polytechnique de Grenoble, Grenoble, France, in 1984, and the Doctorat National Ph.D. degree in fluid mechanics from the University of Aix-Marseille II, Marseille, France, in 1988.

He spent three years as a Postdoctoral Research Associate at the NASA/GSFC/Wallops Flight Facility, Wallops Island, VA, USA. He is currently responsible for the Oceanography from Space Laboratory, IFREMER, Plouzané, France. He has experience in applied mathematics, physical oceanography, electromagnetic waves theory, and its application to ocean remote sensing.

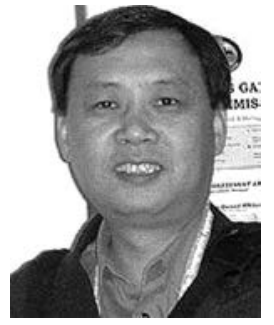

Moonjin Lee received the Ph.D. degree in physical oceanography from the Pukyong National University, Pusan, South Korea, in 1996. He is a Principal Research Scientist at the Korea Research Institute of Ships and Ocean Engineering and a Professor in Ocean Science and Technology School, Korea Maritime and Ocean University. He has been working in development of oil spill response technology, especially oil spill trajectories prediction modeling for 20 years. He has managed many national projects on oil spill response and published over 100 papers and reports. 